\title{
Philosophy and Science, the Darwinian-Evolved Computational Brain, a Non-Recursive Super-Turing Machine \& Our Inner-World-Producing Organ
}

\author{
Hermann G. W. Burchard \\ Department of Mathematics, Oklahoma State University, Stillwater, OK, USA \\ Email: skeptiker@icloud.com
}

Received 23 November 2015; accepted 17 January 2016; published 20 January 2016

Copyright (C) 2016 by author and Scientific Research Publishing Inc. This work is licensed under the Creative Commons Attribution International License (CC BY). http://creativecommons.org/licenses/by/4.0/

\section{Abstract}

Recent advances in neuroscience lead to a wider realm for philosophy to include the science of the Darwinian-evolved computational brain, our inner world producing organ, a non-recursive super-Turing machine combining 100B synapsing-neuron DNA-computers based on the genetic code. The whole system is a logos machine offering a world map for global context, essential for our intentional grasp of opportunities. We start from the observable contrast between the chaotic universe vs. our orderly inner world, the noumenal cosmos. So far, philosophy has been rehearsing our thoughts, our human-internal world, a grand painting of the outer world, how we comprehend subjectively our experience, worked up by the logos machine, but now we seek a wider horizon, how humans understand the world thanks to Darwinian evolution to adapt in response to the metaphysical gap, the chasm between the human animal and its environment, shaping the organism so it can deal with its variable world. This new horizon embraces global context coded in neural structures that support the noumenal cosmos, our inner mental world, for us as denizens of the outer environment. Kant's inner and outer senses are fundamental ingredients of scientific philosophy. Several sections devoted to Heidegger, his lizard debunked, but his version of the metaphysical gap \& his doctrine of the logos praised. Rorty and others of the behaviorist school discussed also.

\section{Keywords}

Noumenal Cosmos, Metaphysical Gap, Pre-Linguistic Structures (PLS), Transcendental Ego (or Self), Conceptual-Categorical Apparatus (CCA), Logos (or Language) Machine (LM) Phenomena, Their Internal Structural Historical Records (ISHR), Recursive Mathematical Languages 


\section{Science of the Computational Brain, a Non-Recursive Super-Turing Machine}

Recent advances in neuroscience lead to a wider realm for philosophy to include the science of the Darwinianevolved computational brain, our inner world producing organ. Quite recently, the MIT team of Nobel laureate Tonegawa has proved that memory is kept inside individual nerve cells in the brain, vide infra $\S 1.2$ for details.

The ciliate protozoan Paramecium has a highly polyploid macronucleus with $80 \%$ of its genome but at about 500 times the ploidy of the proper cell nucleus, vide infra $\S 1.1$.

On the strength of these facts, we may infer that individual neurons, especially those of the giant pyramidal kind, function as DNA computers. Hence, it now appears that the entire brain system forms a non-recursive super-Turing machine consisting of 100B synapsing neurons each one functioning as a DNA-computer, based on the genetic code, of high speed \& with very large memory ${ }^{1}$.

This suggests a novel hypothesis, which we put forward here perhaps for the first time.

The total system of this 100B synapsing neuron super-Turing machine apparently is capable of non-recursive computations and thus presumably exceeds the standard computing power of any individual computer that is limited by the standard benchmark of Church-Turing computability, as expressed in Church's thesis and so brings us a little closer to possessing an infinite divine spirit ${ }^{2}$. The recursive axiom systems reasonably could be seen as the ones that lead to comprehensible theories. Kurt Gödel proved that no recursive axiomatics exist for arithmetic. Hence, we may deduce that the brain, which appears to be a non-recursive super-Turing machine, may be capable of computing an incomprehensible noumenal cosmos.

The computational brain, the CNS, a powerful computing system, owes its existence to a special case of Darwinian evolution, the adaptation of the human organism to the metaphysical gap that separates an animal's inner world from its outer environment. We prefer to think of it as the outer world, separate from our inner world, formerly our soul, what Teresa of Avila has called the interior castle (Teresa of Avila, 1577).

The super-Turing machine allows the animal to use linguistic descriptors and thereby bridge the metaphysical gap, hermeneutically interpreting its existence in the real world, the environment of experience, vide infra e.g. $\S 2^{3}$.

Bringing science into philosophy creates a new branch, scientific philosophy, that has the advantage of recognizing the inner world not as an abstract metaphysical construct, but as a neural structure, vide infra $§ 1.3$.

The CNS performs neural system operations in a heuristic manner, by investigating phenomena, environmental structures, and establishing for each its logos, linguistic descriptions of their identifying internal structural details putting into words pre-linguistic records of the historical background. In short, the CNS acts as a logos machine.

The most fundamental aspect of this evolutionary adaptation is that through it, the brain offers to the human creature a world map, a logical structure of global context, which is our inner world, a veritable noumenal cosmos, a part of ourselves, our inner man (human), $c f . \S 2.2, \S 2.4$.

Feeling that science is more secure than abstract thought, inclusion of science can take us to a new realm larger than traditional philosophy, similar to a holistic coherence theory of truth. This theme in philosophy is discussed in the S.E.P. article “Truth” (Glanzberg, 2014).

The inclusion in philosophy of neural Darwinism ${ }^{4}$ also should help dispel doubts among philosophers about the reliability of innate human cognition, which must have veracity sufficient for survival of the species, survivors of a grueling 4 billion year race of biological descent. Not so reliable may be sometimes our mental inferences, but these are improving through continuing progress in science and education, and on occasion even our economic and political plans are sound.

Philosophy \& science also are subject matter of earlier work by this author (Burchard, 2005, 2011, 2014).

\subsection{Protozoan Example: Paramecium, the "Slipper Animal"}

The reality of the principle of bio-computing is illustrated well in the ciliate protozoan Paramecium which has a high ploidy macronucleus, that reforms from the proper micronucleus of the animals genome each time after

\footnotetext{
${ }^{1} \mathrm{~A}$ recent estimate found about $84 \mathrm{~B}$ neurons. Half of all neurons are in the cerebellum. For the human cerebral neocortex, the number is $\sim 20 \mathrm{~B}$. This is the part of the brain most directly relevant for philosophy.

${ }^{2}$ Among Alonzo Church's 45 Ph.D. students at Princeton University, Alan Turing in 1938 was the 5th.

${ }^{3}$ Somewhere an explanation is needed, that the gap is nothing very new. It can be identified as a cryptic consensus among Russel, Husserl, Heidegger and Quine (Burchard, 2014). From another point of view, the gap is a cleaned-up version of Plato's cave, a recast form of Leibniz' monadology, Hume's scepticism, or Heidegger's being-in-the-world, etc.

${ }^{4}$ The expression neural Darwinism is used here in the evolutionary phylogenetic sense, not to be confused with Nobel laureate Gerald Edelman's notion of the same name, which concerns ontogenetic development of the phenotype.
} 
mitosis, serving as a good illustration of the computational power of the individual living cell ${ }^{5}$.

Paramecium is fun to watch under a microscope in almost any water droplet from your backyard. As it scurries about it seems to know what it is doing, serving as its own brain cell which is also the single cell of its body including within it all of its organs ("organelles”). Apparently, the macronucleus controls all actual processes inside the cell, suggesting the way DNA functions in neurons in our brain, but inside this single cell creature.

Among ciliates, great variability exists in function and formation of their micro- and macronuclei, and some puzzles remain (Prescott, 1994).

\subsection{Memory Cells}

As mentioned above, Susumu Tonegawa's team at MIT were able to prove (2012) what had long been suspected, that memory is kept inside individual nerve cells, neurons, in the brain (Liu et al., 2012), (Ramirez et al., 2013), (Kitamura et al., 2015).

Combined with what we know and conjecture concerning the ciliate protozoan Paramecium, we may draw this conclusion: Memory is stored inside neurons, spelled out in nature's own language based on the DNA alphabet i.e., in the nucleotide molecular genetic code, the script on which all life depends, available $a b$ initio.

We may infer that memory is linguistic in nature, as biological response to the presence of a metaphysical gap between inner and outer worlds. We have a linguistic brain.

Swayed by the discoveries of the Tonegawa team, a novel view of the computational brain can be foreseen, where individual neurons, especially those of the giant pyramidal kind, function as DNA computers with large memories, and perform at unknown, probably very high speed, the brain system serving as a non-recursive super-Turing machine to maintain whole-life memory, our personal historical records, confirming Henri Bergson. This supersedes parts of the popular Hebbian-connectionist model based on neural nets.

\subsection{The Default Mode Network}

Our main task, combining science with philosophy, should be to know where in the brain to look for the noumenal cosmos (NK), our inner world, not as an abstract metaphysical construct, but as a neural structure in the brain's circuits, recorded at a specific site in the brain in form of a DNA-script.

This may have become easier to accomplish in the recent decade, quite likely having been determined as sited in special brain circuitry, the so-called default mode network (DMN), an automated brain structure. The function of the DMN was discovered by Raichle \& coworkers at WUSTL (Raichle et al., 2001; Raichle \& Gusnard, 2005).

There appear to be two separate units comprised in the DMN, the noumenal cosmos NK proper in the medial prefrontal cortex, and a second part in the parietal cortex, where we find our conceptual-categorical apparatus (CCA), neural centers specializing in conceptual analysis, e.g. mathematics—geometry and algebra—and other systematic logical developments.

In the DMN the brain is analyzing its memory of recorded experiences for a fuller comprehension and greater clarity concerning the actual sequence of events and motives of agents. We may surmise that one of the DMN's criteria is logical consistency, but also completeness, to seek any $\&$ all associations between the huge number of items of available information stored in neurons-predictably unsuccessful because of the Gödel incompleteness theorem — and so the DMN has to go on working ceaselessly, as it does, interrupting itself only when urgent tasks require all of the brain's resources ${ }^{6}$.

Apparently DMN serves as global reference neural site where we keep our interior world NK or world model-global context (WM-GC). This should be a related to W.V.O. Quine's "web of belief," for more, vide infra $\S 2.4$.

\subsection{DNA Language $A b$ Initio}

These recent results again suggest that brain memory, our personal historical records, is kept in linguistic terms based on the DNA/RNA nucleotide alphabet. Remembered events as well as mental concepts and intellectual associations by implication may now be seen as neurally DNA-coded items of our inner world, constitutive parts of the noumenal cosmos WM-GC.

${ }^{5}$ The Genoscope Institute, located near Paris, France, has sequenced the DNA in both of Paramecium's nuclei, finding the macronucleus contains about $80 \%$ of the genome, but at about 500 times the ploidy of the proper cell nucleus.

${ }^{6}$ Here, we are ignoring finite memory and finite computing steps. 
This alphabet has served as a foundation of life on this planet functioning as the control language of the ribosome machine that runs protein synthesis under control of the cells genome. This may well be a derivative of more basic logico-linguistic operations existing in unicellular protists. The nucleotide alphabet also appears to maintain mental functions in all higher animals, and analogously works in similar manner carrying information in the broadest sense even in unicellular biota and in plants and fungi. This establishes a tie between life and the concept of formal languages.

\section{Adaptive Darwinian Response to the Metaphysical Gap between Inner and Outer Worlds}

It is the strangest thing in science, an enterprise crowned with enormous success, especially in her study of our human physical organism where science has had such beautiful \& complete results, our scientific \& philosophical organ, the brain, that has done all this great work, this particular organ is the least understood. Investigating the brain is a very complicated matter, of course, considering that it would have to be at least as complex as the world that it comprehends, which is its main task, its main information highways choked with traffic of our daily chores, but there are the many minor service roads and tunnels, that carry the cross-talk of mental associations, correlations, and inferences. But perhaps, in this our present age we are at the threshold of new discoveries in this regard, both by science and by philosophy, and we just might succeed a little better if we combine the two.

\subsection{A "Paradigm Shift" to Scientific Philosophy}

In philosophy up until today, humans have detailed how we comprehend subjectively our experience, as it is being worked up by the computational brain, a super-Turing machine, as described above, vide supra $\S 1$. Put another way, philosophy has been rehearsing the human-internal world, the noumenal cosmos, a beautiful painting of the not-always-attractive \& indeed often disorderly, messy outer world, the chaotic universe.

But now it may be time for a new, a wider, broadened horizon, a "paradigm shift," where philosophy among subject matters of her investigations, is to include, not ignore, the biological means of how humans understand the world that have come to exist as a result of Darwinian evolution in a very special case, best described as metaphysical evolution, that brings about adaptation in response to the metaphysical gap that opens up to an existential chasm between the human animal's inner world and its outer environment \& shapes the creature's organism so it can deal more easily with the great variability of its world and with the daily changes in the contingencies as such arise.

This new direction of inquiry may then rediscover philosophy's original aim \& purpose to understand the origin our inner neural world, the noumenal cosmos, and why it should have turned out suitable for our survival in the outer world of our environment through the necessity of Darwinian evolution, and how it can be a bridge across the metaphysical gap, a deep cleft or abyssal chasm, that stretches between the noumenal cosmos, our inner world with its orderly arrangement, and environmental phenomena, natural structures growing in the chaotic reality of the outer world of the universe.

\subsection{The Interior Castle \& the Inner Man}

In all ages and on many occasions people have fully grasped that deep in ourselves, in our inner world, what Teresa of Avila has called the interior castle, there resides a source of confidence that our efforts are not in vain, are not aimless fruitless stumbling but can be ordered beneficially based on an overall perspective, a global context, $c f$. below next $\S 2.4$, a philosophy of life, that is the very essence of who we are as human individuals. Often mentioned as an example is Victor Frankl, concentration camp survivor and psychiatrist, $c f$. Stephen Covey (Covey, 1989: p. 69). Generally among devotees of many of the world's religions, there never has been any doubt that human life resides in our inner being, our human soul ${ }^{7}$.

But always the reality of the inner man has been in doubt, and under attack from the materialist-behaviorist side, so now, it is up to the neural approach to provide clarity regarding this vital topic.

For Paul, the apostle, in his epistle to the Romans a struggle for moral purity is fought by the inner man, है $\sigma \omega \stackrel{\alpha}{\alpha} \theta \rho \omega \pi \circ \varsigma$, against our sinful members, an important consideration which culminates in Christian faith teaching that our material organism is not who we are.

${ }^{7}$ So uniformly in Christianity, Hinduism, Taoism, and Confucianism, and others. 
An excellent survey of how the thoughts of Plato and Aristotle relate to the NT writings of Paul is given by Robert Hoerber (Hoerber, 1977).

\subsection{Opposing Inner \& Outer Worlds}

The concept of an opposition of outer $\&$ inner worlds has a long history, illuminating the metaphysical gap between the two worlds \& its various forms, including the related inner man-outer man complex, $c f$. § 2.2 above.

Immanuel Kant in his Critique of Pure Reason begins with a doctrine of two kinds of sensual experience, by the inner temporal or by the outer spatial sense (Kant, 1781a, 1787b), quite possibly under an early influence as a young person by what he had learnt from church traditions \& teachings.

External signals impacting our body, sense data in traditional language, originate in the environment including our own physical organism, are picked up by sensory neurons, digitized, carried along cranial \& spinal nerves and transmitted to the brain. The neural signals carry information about the outer world, extracted and fitted into the noumenal cosmos by the logos machine, the logical association centers of the brain, vide supra $\S 1$.

This neural anatomy is utterly compelling and provides fundamental evidence for how the metaphysical gap is bridged.

Going back to Helmholtz, the fitting process has been understood under the name of [global] context update by physiological psychologists, who typically work with the EEG. In the experiments, the context update shows up as a positive voltage, the "P300 ERP,"-Event-Related Potential—at $300 \mathrm{~ms}$ elapsed time after the "stimulus," i.e., the reception of the external signal (Burchard, 2011).

Carried along cranial \& spinal nerves, these signals from the brain's physical environment are completely separate from and have nothing to report about our active thoughts, conscious interior musings and mental reflections dealing as they do with any and all aspects of our lives that together constitute our very own inner world.

Neural information transfer belonging to conscious processing internal to the brain presumably is centered at the Ego neural clusters, typically Brodmann areas BA 10 - 12, in the orbito-frontal (fronto-polar) cortex. For the study of such internal processes there do exist a few programs in neuroscience, e.g. in the areas of mind-wandering and of prayer, that hold much promise for future demonstrations. But this matter does not seem to be very well understood by neuro-psychologists, who tend to refer to it as introspection, a term with unfortunate pejorative connotations.

A neural basis exists for I. Kant's temporal-inner vs. spatial-outer sense split, realized in lateralized hippocampus function, which is left-lateral for sequential memory vs. right-lateral for place memory, as recently discovered by Christian Doeller's Nijmegen team, $c f$. (Burchard, 2011) for more.

\subsection{Global Context \& the Linguistic Brain}

In our considerations of philosophy as science of the brain, and of its Darwinian evolution, we must start with the adaptive forces confronting a living creature, plant or animal.

All animals for survival need GC, although comprising more or less depending on the species, for finding their way around, foraging for food, mating and reproducing: raising their young, \& for fending off predators and enemies.

A functioning brain needs to be informed both about what we may expect and about the world as it is at this instant. The first requirement implies a complete data base, all of the past, so we can put into global context whatever it is that may be dished up to us by the second requirement of global receptivity.

To clarify the concept of the brain's—or the Ego's—global receptivity, here we are referring to what in neuroscience is known as a neuron's receptive field, perhaps best defined as the spatio-temporal region in the environment from where at any given moment signals can reach the particular neuron. Typically, in primary visual cortex area V1 the receptive fields are small, but increase progressively as images move up to V2, V3, etc. It is our hypothesis that at the apex of the brain, where sensory cortex terminates in orbito-frontal clusters, and motor cortex begins, the seat of Ego making its decision for what the individual will do next, in the great input-output loop which the brain is, that here receptive fields are global, unlimited in time and space.

Global context is the biological version of Brentano's intentional in-existence, and of Heidegger's "as." Indeed, global context enables human opportunism, our capacity to grasp what it is in the environment from which we may able to benefit, resources that might help us in our struggle for survival. 
Items of every conceivable sort are included in GC, whatever is known, has been encountered, in the life of the individual animal, as well as the totality of data, known or knowable by logical analysis, mutual relationships or associations, enabling the animal to relate its actions, its plans, \& and all of its internal processes to the totality of the environment. This is very similar to D.H. Ingvar's “memory of the future,” cf. (Burchard, 2011) for more.

Philosophy herself is a result of brain evolution, and it would follow that Darwinian adaptation very likely may illuminate epistemology, evolved brain structures, global context \& global receptive field, even perhaps help explain consciousness.

The linguistic-computational brain functioning as a logos machine discovers phenomena and reveals their internal structural historical records ISHR, under the rules of formal linguistic dualism (Burchard, 2011, 2014). The linguistic brain provides global context \& global sensitivity, tames chaotic reality into a noumenal cosmos, \& precariously bridges the metaphysical gap by a trusswork of formal languages, subject to look-up in the encyclopedic noumenal cosmos and with concurrent P300-type update with help from the conceptual-categorical apparatus sited in parietal cortex, analyzing pre-linguistic structure.

We note in passing that here in linguistic dualism there is no vitalism, no Cartesian dualism hiding out from the views of materialist thinkers. All logical processes are mediated by material physical structures, like your smartphone depends on metal, plastic and glass, the brain cannot do without neural tissues. Entities in the very same outer environment carry the inner world, and although recorded under supervision of the transcendental Ego or Self, are operated by neural clusters in the orbito-frontal (fronto-polar) cortex.

\subsection{Heidegger's Lizard and Its World}

A great case for us to illustrate the methodology of applying scientific philosophy to a specific, important text is given in the example of Heidegger's lizard basking on a stone, that occurs in his 1929/1930 Winter Semester lectures (Heidegger, 1929/1930, 1983).

This popular text is quoted widely, with approval, $c f$. (Broglio, 2008), (Oliver, 2007).

Heidegger's text, translated, p. 196-198, runs as follows.

The stone is without world. The stone is lying on the path, for example. We can say the stone is exerting a certain pressure upon the surface of the Earth. It is "touching" the Earth. But what we call "touching" here is not a form of touching at all in the stronger sense of the word. It is not at all like that relationship which the lizard has to the stone on which it is lies basking in the sun. And the touching implied in both these cases is above all not the same as that touch we experience when we rest our hand upon the head of another human being. It is true that the rock on which the lizard lies is not given for the lizard as rock, in such a way that it could inquire into its mineralogic constitution, for example. It is true that the sun in which it is basking is not given to the lizard as sun in such a way that it could ask questions of astrophysics about it and expect to find the answers. But it is not true to say that the lizard merely crops up as present at hand beside the rock, amongst other things such as the sun for example. When we say that the lizard is lying on the rock, whatever the lizard is lying on is certainly given in some way for the lizard, and yet is not known to the lizard as a rock. Rather we imply that whatever it is is not accessible to it as a being.

Here, the primary point for our discussion in the manner of scientific philosophy is Heidegger's central metaphysical topic of the Seinsfrage, the experience by an organism of something "as" something, in this case, the lizard's experience of the rock as a rock, which he is denying, stating it does not take place.

For our consideration, it should be clear that the rock "as" a being is merely paradigmatic for any "being." Indeed, this is exactly how Heidegger's claim is interpreted, and his view accepted generally, by numerous authors as a good way to think about how people differ from animals, who read his 1929/1930 lectures for promoting the doctrine that only humans are capable of experiencing any being "as" a being of a certain kind.

But the point is refuted easily by putting another entity in place of the lizard's rock. Let us think of a visitor to the Roman Coliseum who observes a lizard basking in the sun on one of the fallen marble pillars and attempts to catch it with his hand. Likely he will fail, and instead will see the animal, quick as a wink \& bending itself in a sinuous curve, slink in the opposite direction off of the rock and disappear from its place in the sun. Of course, our humble vertebrate cousin the lizard just like we ourselves would, has relied on his GC-WM and recognized the visitor for a deadly foe.

${ }^{8}$ Our term “something” becomes “a being” in his terminology. 
It seems that Heidegger in his argumentation is ignoring that the CNS of all species of vertebrates is built on basically the same plan, although a lizard's would be lacking some of the features included in brains of e.g. mammals and especially primates, albeit on the plan of a super-Turing machine with a slightly smaller capacity. This allows for detail and development under Darwinian rules of evolution. So, it is difficult to imagine any major categorical distinctions between humans, at the top of the primate scale, and mammals or even vertebrates.

Proceeding to bare aspects of scientific philosophy of this quoted text, we focus on how Heidegger's reflective habits are in the way of his understanding his own logic: His derivative dwelling on complexity of experience is masking for him the immediacy of his own experience, what he might observe when interacting with the agile reptile.

The tiny creature certainly had no concept of the rock "as" a marble column quarried by the Emperor Titus when he built the Coliseum and no concept of Roman history, that this took place shortly before Titus was murdered by his brother Domitian", but he had no trouble identifying the visitor "as" another animal trying to grab it with an implied threat to its life.

A secondary point is his assertion that "whatever the lizard is lying on is certainly given in some way for the lizard." Heidegger is subject to the common fallacy of the given object. It is only by applying our logos machine that we are able to delve into the resources of our internal world model, the noumenal cosmos, and reconstruct an empirical phenomenon, that is construed as a "given" object (Burchard, 2014).

\subsection{Holism and Conscious Ego}

Global context, provided by the bipartite DMN, is equally as fundamental to the functioning of conscious Ego as is the global receptive field of neurons in the fronto-polar cortex, and both combine to the holism which we observe in our day-to-day dealings with the environment and with ourselves.

Widely accepted today by philosophers, a doctrine of holism demands that all of our knowledge must fit together, as a complete "web of belief," (Quine \& Ullian, 1978) and must provide global context from which to judge any particular cognitive domain. The status of this belief is in dispute, the more traditional opinion being in favor of a stronger assertion, a web of knowledge or of information.

As a role of conscious attention, there is a check on the largely automated suggestion of response-list. How the brain exactly achieves this, is not yet known at this epoch. However, there seems to be a connection with global receptivity, meaning global receptive fields for the neurons of our cerebral cortex in the part located just above the eyes, named the frontopolar or orbito-frontal region.

\section{Scientific Philosophy Studies Her Antecedents}

The human soul functions as a logos machine to extract logos, perhaps vaguely definable as structure-in-historical context, from phenomena. However we are at pains that structure as a basic mathematical vocabulary remains undefined and may be undefinable, lacking reference to a global context philosophy that permits us to speak of mathematics as an integral part of the same global context.

The soul has not been talked about much in the recent age, and yet the ancients held it to be a supreme and delicate reality of inestimable value. Right conduct and a virtuous life was expected of every man ansd woman to protect one's soul from being damaged or soiled.

Here, we propose that the human soul can be found living in the linguistic brain, that forms its perishable home, the necessary organismic substrate for its material existence.

The linguistic brain, the logos machine, is ceaselessly engaged in gathering data for and updating-revising a world model which is internally held by the living animal in prefrontal cortex ${ }^{10}$, and required as a foundation for the global context in order to provide it with insights needed by the living animal that it must have available so it can know what it is doing at all times.

\subsection{Heidegger's Sein Und Zeit Inspires This Current Essay}

Needless to say, Heidegger does not develop his thoughts in the idiom of a neuroscientist, but in terms of his idiosyncratic language of hermeneutics, cultivated by him since his great but early work, Sein und Zeit (SZ),

\footnotetext{
${ }^{9}$ This account of how Titus died is not firmly established from contemporary records.

${ }^{10}$ Or analogous structures in the pallium perhaps of lower vertebrates without cerebral neocortex, and even arthropods.
} 
his fundamental ontology still widely considered his magnum opus (Heidegger, 1926, 1979).

When reading SZ, one is struck by the manner in which Heidegger outlines his concept of inner-worldliness, man's being-in-the-world, his constant care, confronting the furniture of an alien world, suffering exposure to talk, chatter, gossip, and enduring his existence in his "Dasein."

In many ways, this is all quite similar to our account here in the present essay of the metaphysical gap, of the inner man-inner world $v s$. outer world division that one might venture to claim an isomorphism to exist between the two, and that this author is composing this essay under the spell of Heidegger's SZ and that our view is merely a scientist's thinking of how to reconcile science with the philosopher.

Hermeneutics, the study of linguistic interpretation, is a part of Heidegger's methodology since his famous magnum opus "Sein und Zeit" and beyond. Language plays a key role often celebrated in Heidegger's work, gathering the logos of our experienced world, putting into words awareness of the cosmos, in the inner world that provides us with global context required to understand our lives, how we live.

The doctrine of the logos is developed in Heidegger's 1935 lecture course EM (Heidegger, 1935, 1998), where the metaphysical gap plays a major role albeit in a different guise, as separation of being and thought, $c f$. $\S 3.2, \S 3.3$. The logos is an established bridge across the metaphysical gap empowering an animal to live in its environment. Our understanding of the logos depends on the connection with mathematical formal language theory, vide supra $§ 2.4$.

\subsection{Heidegger and the Metaphysical Gap}

A prime motivation for this investigation has been our interpretation of Heidegger's EM, his metaphysics lectures (Heidegger, 1935, 1998), due to Heidegger's interesting version of the metaphysical gap that we believe is a lasting contribution.

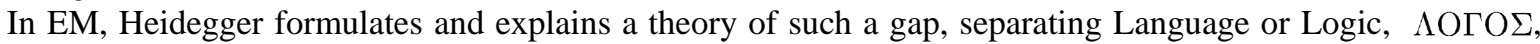
from Nature, $\Phi \Upsilon \Sigma I \Sigma$, a gap that is mentioned in EM explicitly and often, which we like to call the Heidegger separation or Heidegger chasm.

Heidegger believes a separation of Being and Thought to be the result of an historical process affecting the Western mind that dates back to the ancient Hellenic philosophers and onward, and today presenting an unbrid-

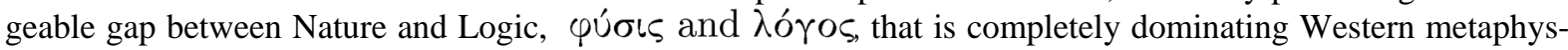
ical thought, and determines the present condition of the Western mind.

Unlike Heidegger, we see the gap, not as the result of history, but to the contrary, as an invariant structure that naturally exists between the human animal and its environment, so that the Heidegger chasm is subsumed by the metaphysical gap.

We also feel encouraged in this view by work of Thomas Sheehan, who has concluded that reading Heidegger's EM and metaphysics generally, we everywhere should replace the word "being" by "disclosure of being" (Sheehan, 1999).

It is important to note that some eight years after delivering his EM lectures he continues much of his train of thought from EM in his 1942/43 winter semester lectures on Heraclitus and Parmenides, published posthumously as Parmenides (Heidegger, 1943, 1982).

The topic of these later, war-time lectures extends in seamless fashion his 1935 work, proving that he never abandoned his metaphysical avenue of thought, as is widely claimed, merely seeming to be divergent.

He himself said as much, quoting from Clare Pearson Geiman (Pearson Geiman, 2001):

Heidegger insisted that his later thinking developed out of the earlier and did not in any simple way invalidate it.

In EM, at one point in his discussion he develops a theme, giving a general explanation of thought, which has the flavor of the duty that we ascribe to CCA when the human animal is engaged in recognizing the environment. A brief quote will illustrate.

EM, p. 90: ...thought brings something before us, represents it. This representing always starts on our initiative, it is a free doing and ordering, but not arbitrary. Rather, it is bound by the fact that in representing we think upon and think through that which is represented, as we dissect it, lay it apart and back together again.

The representational part may surprise some Heideggerian scholars here. His ruling contrast being-thought must come from inner unity that exists between disclosure of being and the thoughtful reconstruction of an empirical phenomenon. And, this is a clear reference to the metaphysical gap, in a way this is about the commonplace distinction between Reality, the "what-is" vs. "what we think." We need to better comprehend thought be- 
fore there can be any progress on this issue.

EM, p. 91: Thinking, besides desiring, willing, and feeling, is one of our powers. In the exercise of all powers and behavioral modes we relate to what-is, not only in thought. Of course, but the distinction "being and thinking" involves something more essential than a mere relation to what-is. The differentiation springs from an initial inner union between thought and being itself. The designation "being and thought" invokes a distinction that in a way is demanded by being itself.

This quoted passage again reminds us of our brain function that we have to rely on global context as revealed by scientific philosophy for Heidegger's man-as-Dasein to prevail in the struggle of existence.

Under its own guidance moment by moment Ego, the logical unit operated by the orbito-frontal cluster with its global receptive field and with support from NK plus CCA DMN, hermeneutically interprets our experience of the world.

Neurologically, this is based on Top-Down Processing, with the lower order processing centers instructed by Ego, which in turn is guided by Order and Beauty to prevail while building up the Interior Castle, or noumenal cosmos

\subsection{Heidegger's Doctrine of the Logos}

Heidegger's doctrine of the logos is of great help for understanding how the mind is able to bridge and transition the metaphysical gap, which is accomplished in the application of the CCA and discovery of the logos of phenomena, their internal strucural historical record (ISHR).

One of Heidegger's main points is the relationship of language \& logic, leading to the ontological discovery of a foundation of both in the vocabulary $\lambda \hat{\varepsilon} \gamma \varepsilon \iota \nu$, usually translated as reading but with the basic meaning of gathering ${ }^{11}$.

He endeavors to show that formal logic as a source of understanding leads to a dead-end-lane, clearly not foreseeing the dramatic rise of computer engineering from that field. In a lengthy passage quoted next of a basic transition from our naive understanding of logic, and of mind vs. being, we very quickly make valuable progress and discover the linguistic nature and foundation of mind, which is a major point of this essay.

EM, p. 91: Moreover, she [logic] is the one science and that discipline within philosophy, where ideological standpoints and movements play little or no part. Furthermore, logic is considered as a reliable and trustworthy science. She has taught the same thing since antiquity. True, one logician may rearrange the various traditional disciplines with regard to their structure and order, another leaves out this and that, another brings in additions from epistemology, yet another undergirds everything with psychology. But on the whole, a gratifying agreement prevails. Logic relieves us of the trouble of laboriously investigating into the nature of mind.

And yet-we should like to raise one question: What does "logic" mean? The name is an abbreviated expres-

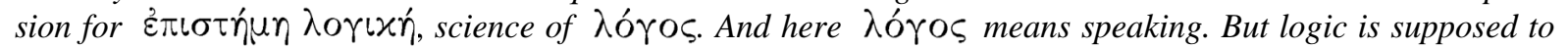
be science of thinking. Why then is logic the science of speaking?

Do we really need to start with speaking in order to identify thinking? This is far from self-evident. Previously, we explained "thinking" without any reference to speaking and speech. Therefore, reflection on the nature of thought if it is done as a reflection on $\lambda o ́ r o s$, and thus becomes [mere] logic, is quite bizarre. "Logic" and "the logical" by no means are immediately the manners of identification of thought, as if absolutely nothing else were possible. On the other hand, it clearly was no accident that the science of thinking became "logic."

We should interject, to prevent a possible misunderstanding, that here he probably meant to say "formal logic," because the general term of "logic" never seems to have lost its basic meaning that most plainly indicates synonomy with "metaphysics."

In effect he maintains that a formal theory of logic explains nothing about how humans can prevail against fate, calling the very idea "bizarre." And indeed he is right. The formal logic is just the machine language of the super-Turing machine that cannot make sense of life unless it first creates its WM-GC. Nonetheless, as a seeming paradox, scientific philosophy recognizes that global context stitched together by the machine is what makes possible for the wretched creature to experience conscious life, love and respect for others.

By the reference to speaking Heidegger reveals that the logos root belongs to linguistic mental grasp, which illuminates the computation, the physis matter supports the events and makes the final record possible, but remains blind to the calculated result.

\footnotetext{
${ }^{11}$ As in gleaning grain, after the harvest.
} 
The true logic begins to emerge in the final sentence of the succeeding paragraph, after a critique of "logic" in quotation marks and it now must be secured.

EM, p. 92: We seek, in service of thought, to win precisely that from where the nature of thought determines

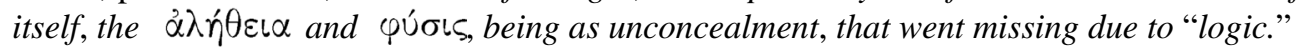

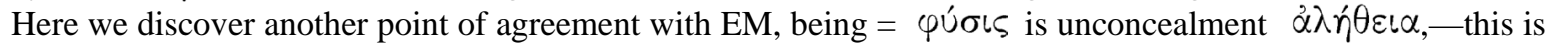
where we arrive with the help of thought, we learn "truth", the proper arrangement of the noumenal cosmos, which we may identify with Heidegger's "open," by applying our CCA to sensory observation of outer world phenomena.

This is precisely the function Kant taught us in his famous Transcendental Deduction, that we control experience by our thought processes required for discerning the true facts of actuality in the world that surrounds us at any given moment of time, being aware of the thoughts as our Ego is able to experience its own actions, where "experience" is a euphemism, a misnomer, a circumlocution for the actual event, about which all we can truthfully claim is that Ego is receptive toward its own actions, which is safe for us to assert, taking advantage of Ego's global field of receptivity.

Heidegger continues to develop his doctrine of the logos, combining Parmenides with Heraclitus, to disprove their supposed divergence, and explaining their essential identity, by engaging in a full-fledged discussion and

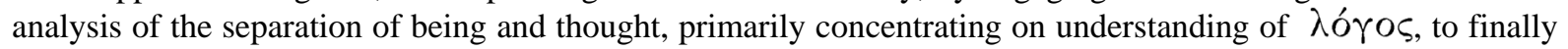
complete the doctrine with an enigmatic reversion, countermanding the Aristotelian interpretation of man as a

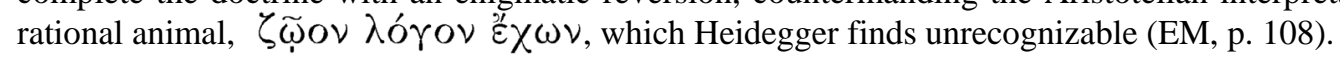

The central fact to be unearthed at this point is Heidegger's doctrine of the logos. Dasein is the logos (language) machine, but so that unlike Aristotle, he sees man as defined by logos, not so much owning it. However, this he puts in pointed form at the end of his analysis, quoting:

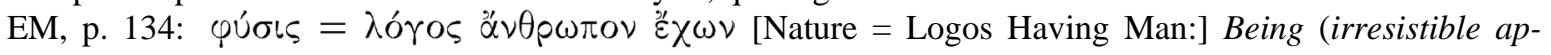
pearance) requires gathering which is what makes being-human.

Put in the vernacular, and perhaps expanded a little for clarity: "Nature equals the Logos in possession of a human mind."

Doubtlessly, here we are receiving, in a nutshell, Heidegger's main result of EM (translated and paraphrased). The simple formula does resemble something akin to science, perhaps amounting to a program for future study in natural philosophy or scientific philosophy.

\subsection{Further Examples of Applying Scientific Philosophy to Extant Works of Philosophy}

Above, the relevance of brain science for the example of Heidegger's lizard, vide supra $\S 2.5$, has shown a first application of brain science to an existing work of philosophy.

As a conjecture and a possible subject of future investigation, the thought patterns of philosophers, the dictionary of their concepts and categorical architecture, themselves, are reflections of pathways in the brain, and of modularized brain functions that are localized in specific neural centers.

On occasion, philosophers seem to be formulating hypotheses that palpably resemble descriptions of brain processes, but, relevant neural considerations are not mentioned yet could be adduced.

\subsubsection{Richard Rorty}

The subject matter of philosophy, since Plato, has been the capacity of the human soul to acquire a comprehension of reality, to understand how $\mathrm{H}$. sapiens can perceive a whole world out of sensations, \& survive by acting in it. This we interpret as the quest for acquisition of a global context through the brain's unceasing running of the DMN.

Similarly, Richard Rorty (Rorty, 1979) in his "Philosophy and the Mirror of Nature" (PMN) frequently discusses the importance of context, that he sees as the source of intentionality, and we can agree with him on holism which is another way of saying that global context is indispensable.

PMN, p. 33:

Again following Wittgenstein, we shall treat the intentional as merely a subspecies of the functional, and the functional as merely the sort of property whose attribution depends upon a knowledge of context rather than being observable right off the bat. We shall see the intentional as having no connection with the phenomenal, and the phenomenal as a matter of how we talk. 
Depending on our view of scientific philosophy, we would say that here he entirely misses the empirical, i.e. observational and hence phenomenal, basis of the noumenal cosmos, which is the source of our intentionality, and although a synthetic creation of the computational brain, partly genetic in origin by evolution, in the final analysis still has empirical roots.

Rorty even expresses the desirability of, in his terms, an "ultimate context," an idea worth pursuing although not quite the same as our global context, beginning on page five of PMN.

PMN, p. 5:

It is against this background that we should see the work of the three most important philosophers of our century-Wittgenstein, Heidegger, and Dewey. Each tried, in his early years, to find a new way of making philosophy "foundational"-a new way of formulating an ultimate context for thought.

Indeed, the kinship of his ultimate context with our global context qua noumenal cosmos is most apparent near the conclusion of his great and difficult work.

PMN, p. 389-390:

If we see knowing not as having an essence, to be described by scientists or philosophers, but rather as a right, by current standards, to believe, then we are well on the way to seeing conversation as the ultimate context within which knowledge is to be understood. Our focus shifts from the relation between human beings and the objects of their inquiry to the relation between alternative standards of justification, and from there to the actual changes in those standards which make up intellectual history.

Here, Rorty accepts a definition of knowledge, with holism implied by reliance on communal consent expressed in conversation, a strengthened version of the coherence theory of truth, but diverted from the essential function of science by what appears to be disregard for the Darwinian origins of human intelligence, and not considered in relation to global context.

To understand anything we require a global context, i.e., we must first comprehend everything, is the holistic thesis that we are defending in this essay, but for Rorty, his "everything" is merely what the conversation requires.

Rorty's PMN amounts to an elaborate explanation that knowledge is what emerges in communal discourse, as agreeable to participants, based on the behavior of those present, so Rorty, who does see himself as a behaviorist, investigates social conversation and vocabularies.

Such a social group consent would be valuable even when viewed from scientific philosophy perspectives, if each individual can vote in favor of a statement of phenomenal facticity of actual empirical structures, or even some noumenal construct from science or the humanities, based on his or her monadic inner world global context, - but this justification would have had no chance of satisfying Rorty from his behavioral formation, under which there is no reality to inner worlds, and no sphere of global context.

One might also ask him if he would not seem to leave the Neanderthal hunter out in the cold, who all by himself, alone beneath glaciated hills, was trying to figure out how to get near a game animal. Clad in furs, the ancient progenitor of today's civilized man had no social group for conversational justification, although on occasion he may have been with a hunting party.

Rorty explains knowledge while discussing what he calls "Locke's Confusion of Explanation with Justification” in one of his chapter headings, referring to T.H. Green's 1874 introduction to Hume's Treatise (Green, 1968).

PMN, p. 141:

Green's distinction between an "element of knowledge" and "the conditions of the organism" reminds us that a claim to knowledge is a claim to have justified belief, and that it is rarely the case that we appeal to the proper functioning of our organism as a justification... Why should he have thought that a causal account of how one comes to have a belief should be an indication of the justification one has for that belief? The answer, I think, is that Locke, and seventeenth-century writers generally, simply did not think of knowledge as justified true belief.

In this quote from Rorty's book, he indeed alludes to and makes indirect reference to science aspects, e.g., in two of his terms. First, "justified" could refer to "fitting in with the rest of the noumenal cosmos," while "belief" is an indication of mental reflection over the global context.

The problem with this as far as apparent from the discussion is that the reference is not explicit, and therefore the noumenal cosmos dependency cannot become part of the discussion. Thus the essential issue of the metaphysical gap is completely off the table for Rorty ${ }^{12}$.

\footnotetext{
${ }^{12}$ One might say that "proper functioning of our organism" is a side-swipe aimed to forestall any serious involvement of science in his discussion.
} 
This traditional definition of knowledge still is widely accepted, decades after Richard Rorty. But, under the auspices of scientific philosophy, knowledge as true belief no longer even makes sense. Instead, everything that we know should be understood as being subject to global context, and the latter as provided by locating the item to be known in the noumenal cosmos.

There is a hint here that John Locke theory of knowledge, may not have been as far off the mark as Richard Rorty and Gilbert Ryle believe, when properly interpreting his ideas as neurally DNA-coded items of our inner world, that should be seen as identifiable with Heidegger's world. Biologically, we are dealing with a function of the neural centers in DMN, located in the dorso-medial prefrontal cortex.

All associations of the item are being checked and re-checked by ceaseless activities in these neural association centers. Such data bases in the form of neural conditions can be acquired only through thoughtful observations of the environment, explained by Kant in his transcendental deduction, a metaphysical theory of how knowledge is established.

While science is rooted securely because of her Darwinian evolutionary foundation, which is why science based explanations have that unrivaled clarity, the traditional vocabulary of philosophy can only allude to scientific reality, and tends to lead to that peculiar subjective style of arguments, urgings, opinions and isms, that modern analytic philosophers seem to be fond of, including many of the luminaries, like Quine, Sellars and Rorty.

\subsubsection{William Bechtel}

The behaviorist view of epistemology espoused by Rorty is not just an out-dated matter from the history of philosophy, as may be seen from this quote from William Bechtel's recent book (Bechtel, 2012).

And if the concept knowledge means justified true belief, then we know that only true statements can be known.

\subsubsection{Henri Bergson}

A rare case of explicit mention of a cerebral mechanism is given by Henri Bergson in his account of the autobiographical memory of the human mind (Bergson, 1911):

...the past is preserved by itself, automatically. In its entirety, probably, it follows us at every instant; all that we have felt, thought and willed from our earliest infancy is there, leaning over the present which is about to join it, pressing against the portals of consciousness that would fain leave it outside. The cerebral mechanism is arranged just so as to drive back into the unconscious almost the whole of this past,...

Indeed, philosophers could, following Bergson's example, systematically make the point to see what they are doing from a scientific point of view, and thereby provide their own meta-context.

\subsubsection{Trish Glazebrook and Martin Heidegger on Science}

The human soul was held by the ancients to be a supreme and delicate reality, of inestimable value, guarded and nourished carefully, to keep it pure and undamaged. Today, the soul is suspected of hiding somewhere within the human organism that provides her with a perishable home. The soul is a necessity for a human to act as a holistic being, i.e. a gestalt, who is self-governing his or her own life, which is our interpretation of what Heidegger intended with being-in-the-world.

In Trish Glazebrook’s work on philosophy of science we can find formulations that characterize Heidegger's outlook in words that bring him especially close to ours, which is centered on the metaphysical gap, in particular in "Heidegger and scientific realism” (H\&SR) which is of interest here for us (Glazebrook, 2001).

H\&SR, p. 363 (3 of 42):

...he is a realist committed to the transcendent actuality of nature...

H\&SR, p. 364 (4 of 42), \& note 7, p. 396 (36 of 42):

I put aside...the argument that permeates his early texts that philosophy itself is a science...

This can be found in (Heidegger, 1989: pp. 11-15).

H\&SR p. 366 (6 of 42):

Likewise, Heidegger holds that the basic concepts of a science can undergo radical revision in moments of crisis (SZ, 9/29).

Similarly, Trish Glazebrook also suggests to engage scientific thought within philosophy, and makes "the wholesale change of reference required by a Kuhnian paradigm shift” (Glazebrook, 2001). 
The basic issue perhaps can be put as that when we think about thinking we should go about that enterprise in the most comprehensive manner possible, inclusive of taking a look at the biological organ, the brain that does the thinking.

A typical example for that missing the point that can be attributed to a failing scientific interest in philosophy is seen in the following passage where she discusses a work by two authors (Glazebrook, 2001).

H\&SR, p. 385 (25 of 42):

But Dreyfus and Spinosa argue that Heidegger falls short of the robust realist position, which they describe as a commitment to the independence thesis: that we can have access to things as they are in themselves independent of our practices.

Observe the quoted authors Dreyfus \& Spinosa are considering “access to things” without apparently being interested in any organismic (i.e., neural) structures that might be able to secure such an access, and that could supply details about its nature and neither does Glazebrook call them out on this omission.

Such philosophizing without a science meta-context misses out on depth and realism that could become an asset for future work. Working in this novel science-linked methodology not only would philosophers regularly seek to refresh themselves on work in neuroscience and allied areas, but also in their work habitually take sideways glances at science as an integral part of their thinking deeply about structure in their own thoughts and they might analyze their methodologies to see what brain capacities should be accounted for in support of their proposed hierarchies and psychological effects.

\subsubsection{Thomas Sheehan and Heidegger Interpretation}

Another good illustrative example is the following quote from Thomas Sheehan's essay “The Turn,” (Sheehan, 2009).

The first step would show how human being projectively holds the world open. The second step (the reversal) would show how the meaning-giving world requires human being, such that man is thrown into the meaninggiving process. Both steps were to be worked out in a transcendental-horizontal framework where human being is read as projecting (transcending to) the horizon that confers meaning on things.

He twice refers to the human being functioning as engaged in "meaning" being conferred on the world or entities in the world. We give meaning in our inner world, formerly our soul, by including the item in the noumenal cosmos at its proper place, in the association centers and the DMN where it fits in, a point that Heidegger could be said to stress EM, p.80, although he is using very different words. Sheehan's "meaning giving process” is then something that must happen in the brain as physical agent of the soul, cosmos and global context. As biological organisms, humans are engaged in many things, but always through using one or more of their physical organs, in this case the physical brain, where the human soul is safely harbored, and always involved when it comes to give meaning.

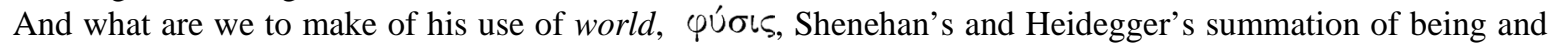
meaningfulness. Sheehan approaches the world issue from a distance, skirting it, but does not make any further inquiry into the relationship between inner man and outer world, which is what we have called the metaphysical gap, and is the main subject of an earlier essay (Burchard, 2014).

Again a miss of reference to our Darwinian endowed CNS can be detected, even more clearly, in the next example from Sheehan's new book (Sheehan, 2014):

For Heidegger, being refers not to the mere physical presence of a thing to the sense organs. Rather, it refers to the meaningful presence of things, which is given only with human beings. Being comes into play with us, with humankind. There is no way I can get around meaningfulness or outside of it I cannot step out of my panhermeneutical skin. Nor should I want to, because for humans, outside of meaningfulness there is only death. I am ineluctably thrown into meaningfulness simply by being human, and I am human only to the degree that I am immersed in meaning. I a priori exceed things insofar as I am always already beyond them, related to their significance. The different and constantly changing worlds I live in as student, worker, parent are saturated with meaning, as is everything that shows up within those meaning-giving worlds. Everything I attend to everything I can mind turns out to make sense, whether actually or potentially.

The commitment to meaningfulness that Sheehan refers to, is a part of our inner world of course, the noumenal cosmos, which is formed by the super-Turing machine, patterned on its genetic structure acquired in eons of Darwinian competition and adaptation, and which it is able to harbor inside the skull, mainly in the medial prefrontal cortex according to Raichle et al., but rooted throughout the brain, and especially inside neurons of 
the Ego-cluster in the supra-orbital cortex with their global receptive fields.

An example of significance for Heidegger students is his famous Ereignis, "owning," or appropriation. The concept could be interpreted as incorporation of an experience into the internally held WM, our noumenal cosmos. In fact, it does seem to cry out for that.

\section{Scientific Philosophy and Society}

For many of today's public debates, a scientific philosophy approach might be helpful for resolving thorny issues, or at least to gain a firmer grasp on them. The helpful point of view will be that none of these can be resolved without recourse to global context which is rarely the case in actuality, where discussions and conversations most often concern minutiae. One aspect of GC is that hypotheses, even extravagant ones, are not as a rule controversial in science. What often is controversial are claims of verification or falsification of known hypotheses. Two particular examples of issue complexes come to mind as having been in the forefront of general attention for the longest, first, the debate about evolution vs. creation, where details of the fossil record can be confusing, and second climate change, and the details of the temperature record. In both cases the adherence to the overall, global connections of issues refusing to get bogged down in details, might help to clarify matters.

One could imagine philosophy to shine with a brighter glow from a higher level of engagement with the brain sciences that might lead to refinements of philosophical theories as a result of more often including insights from neuroscience and allied fields of research as suggested by us here.

There is much that scientific philosophy has in common with several currently thriving research directions, especially cognitive science, a well-established discipline in the sphere of philosophical psychology, a branch of which is occupied explicitly with philosophy (Thagard, 2014). The principal differences come from the hermeneutical analyses of scientific philosophy seeking to validate conclusions by referring items to specific brain centers and actual neural data streams between such brain centers. As illustrated above for Heidegger's lizard, such analyses already can be applied fruitfully to extant writings in philosophy at this time.

Scientific philosophy, using the most recent results from neuroscience, draws on a by now increasingly comprehensive range of insights, which together paint a divergent picture from older, now possibly obsolete ideas about the CNS some of which may continue to be entertained in cognitive science, $c f$. discussion by the Tonegawa team of synaptic long-term potentiation and Hebbian learning in relation to recent advances in cellular memory (Ramirez et al., 2014).

In the past perhaps we simply knew too little about the brain, but this is changing rapidly, as evidenced above, and vividly exemplified by memory cells and DNA computing, although the latter is still hypothetical.

\section{Summary \& Conclusion}

In this essay, we are offering a survey of some fundamental ingredients of philosophy, scientific philosophy basics, in the form of a melange of recent advances of our understanding of how the brain works.

The linguistic-computational brain serves us today after 4B years of Darwinian evolution allowing our organism to adapt to the metaphysical gap that exists between an organism's inner \& outer worlds. Such adaptation is possible due to the availability of the DNA genetic code, life's own language $a b$ initio, so that each neuron can function as a DNA computer, and serve as a finite-memory, finite-time version of a Turing machine. Already at the uni-cellular stage, ciliates possess a macronucleus, a brain-in-the-cell among the protozoan's organelles, one might call it the animalcule's "cerebrelle."

Yet, the entire neural system of the brain—our main interest being in the neocortex—does not seem limited in its computing the way a Turing machine is restricted to (partial) recursive functions, because neuron synapses, typically axon terminals on dendritic spines, are created freely and multiple times. This leads us to suggest that we humans and other animals are being run by non-recursive super-Turing machines for our central nervous systems.

The most important function of the super-Turing machine is to record in memory all that occurs in the animal's life, and from these stores to compute a unified, combined logical account, a world map of global context, the creature's inner world, an orderly description of the universe, that may suitably be referred to as a cosmos, part of our inner selves. The cosmos is a noumenal entity, not reality itself, but the result of applying language to reality cosmetically.

Due to recent advances in the field of neuro-psychological science, it appears more likely at present that phi- 
losophy could benefit by expanding its realm to include consideration of the super-Turing machine. Cognitive brain processing functions depend on structural aspects, such as white matter fiber tracts, and the various known brain centers, including the DMN which seems to be harboring the cosmos.

Perhaps also, benefits would accrue from keeping in mind that global context is a necessary mental capacity, and by thinking about how to order our lives. That job can only begin to be accomplished when we set out to discover global context. This would seem to lead us back to the original true aim \& purpose of philosophy.

In this essay, the utility of such a broadened horizon is demonstrated by considering works of several more recent philosophers, including Bergson, Heidegger, Quine, Rorty, etc., specifically concerning the way difficulties, even errors, might be avoided when taking into account that animals would have to be in possession of a global context, however imperfect, to function normally and survive in their tumultuous environments.

Perhaps philosophizing could be seen best as externally verbalizing the ceaselessly running cortical circuits, the recently discovered DMN, engaged in a continual effort of trying to make some sense at least out of our existences in this world.

The job must remain unfinished, because of the Gödel incompleteness theorem, which is valid for recursive axiom systems that are sufficiently rich. However, there is the surprising aspect that the computational brain now appears to be identifiable as a non-recursive super-Turing machine, so that Gödel's results may not apply after all ${ }^{13}$.

By all available evidence, the work never gets done, the logos machine works full time $24 / 7$, and on its way passes through strange worlds in our dreams. The noumenal cosmos by which we are being served remains unfinished. The resulting global context floats on air.

This universe in which we live ultimately must remain incomprehensible, i.e., non-recursive, because uncountable (Burchard, 2005).

\section{Acknowledgements}

The author wishes to give his thanks to several reviewers of this paper and of an earlier version for their valuable suggestions and extremely instructive and helpful remarks.

In memory of my sister Erika, on her 84th birthday.

\section{References}

Bechtel, W. (2012). Mental Mechanisms: Philosophical Perspectives on Cognitive Neuroscience. London: Kindle Edition, Taylor and Francis.

Bergson, H. (1907, 1911). Creative Evolution. English Transl. of L’Évolution Créatrice. New York: Henry Holt \& Co.

Broglio, R. (2008). “Living Flesh”: Animal-Human Surfaces and Art. Journal of Visual Culture, 7, 103121. http://dx.doi.org/10.1177/1470412907084505

Burchard, H. G. W. (2005). Symbolic Languages and Natural Structures. Foundations of Science, 10, 153-245. http://dx.doi.org/10.1007/s10699-004-3068-9

Burchard, H. G. W. (2011). The Role of Conscious Attention in Perception. Foundations of Science, 16, 67-99. Published Online 18 November 2010. http://dx.doi.org/10.1007/s10699-010-9201-z

Burchard, H. G. W. (2014). The Cognitive Gap, Neural Darwinism \& Linguistic Dualism Russell, Husserl, Heidegger \& Quine. Open Journal of Philosophy, 4, 244-264. Published Online August 2014. http://dx.doi.org/10.4236/ojpp.2014.43032

Covey, St. R. (1989). The Seven Habits of Highly Effective People. New York City, NY: Simon \& Schuster.

Glanzberg, M. (2014). “Truth.” The Stanford Encyclopedia of Philosophy. E. N. Zalta (Ed.). http://plato.stanford.edu/entries/truth/

Glazebrook, Tr. (2001). Heidegger and Scientific Realism. Continental Philosophy Review, 34, 361401. Norwell: Kluwer Academic Publishers, 376 (16 of 42). http://dx.doi.org/10.1023/A:1013148922905

Green, T. H. (1968). Hume and Locke. In R. Lemos (Ed.), New York: Thomas Crowell

Heidegger, M. (1926, 1979). Sein und Zeit (15th ed.). Max Niemeyer. English Translations: Being and Time. J. Macquarrie, \& E. Robinson (1962), London: SCM Press; J. Stambaugh revised by D. J. Schmidt (2010), Albany, NY: SUNY Press.

Heidegger, M. (1926, 1989). The Basic Problems of Phenomenology. Frankfurt am Main: Vittorio Klostermann. English

${ }^{13}$ Of course, there is also the minor issue of dealing with finite memory and finite computing time. 
transl., A. Hofstadter (1988), Studies in Continental Thought, Bloomington, IN: Indiana University Press.

Heidegger, M. (1929/1930, 1983). The Fundamental Concepts of Metaphysics: World, Finitude, Solitude. Engl. Transl. W. McNeill, \& N. Walker, Bloomington, IN: Indiana University Press, 1995.

Heidegger, M. (1935, 1998). Einführung in die Metaphysik. Max Niemeyer. English Translations: R. Manheim, (1959), G. Fried, \& R. Polt (2000), Introduction to Metaphysics, New Haven, CT: Yale University Press.

Heidegger, M. (1943, 1982). Parmenides. Frankfurt am Main: Vittorio Klostermann. English Transl. A. Schuwer, \& R. Rojcewicz (1992), Studies in Continental Thought, Bloomington, IN: Indiana University Press.

Hoerber, R. G. (1977). Immortality and Resurrection: A Critical Exegetical Study. Concordia Journal, 3, 56-70.

Kant, I. (1781a, 1787b). Critique of Pure Reason. Engl. Transl.: M. Weigelt (2008), based upon Transl. by M. Müller (1881), London: Penguin Modern Classics.

Kitamura, T., Sun, C., Martin, J., Kitch, L. J., Schnitzer, M. J., \& Tonegawa, S. (2015). Entorhinal Cortical Ocean Cells Encode Specific Contexts and Drive Context-Specific Fear Memory. Neuron, 87, 1317-1331.

http://dx.doi.org/10.1016/j.neuron.2015.08.036

Liu, X., Ramirez, S., Pang, P. T., Puryear, C. B., Govindarajan, A., Deisseroth, K., \& Tonegawa, S. (2012). Optogenetic Stimulation of a Hippocampal Engram Activates Fear Memory Recall. Nature, 484, 381-385. http://dx.doi.org/10.1038/nature11028

Oliver, K. (2007). Stopping the Anthropological Machine: Agamben with Heidegger and Merleau-Ponty. PhaenEx, 2, 1-23.

Pearson Geiman, C. (2001). Heidegger's Antigones. In R. F. H. Polt, \& G. Fried (Eds.), A Companion to Heidegger's “Introduction to Metaphysics” (Chap. 9, pp. 161-182). New Haven, CT: Yale University Press.

Prescott, D. M. (1994). The DNA of Ciliated Protozoa. Microbiological Reviews, 58, 233-267.

Quine, W. V. O., \& Ullian, J. S. (1978). The Web of Belief (2nd ed.). New York: McGraw-Hill Humanities/Social Sciences/ Languages.

Raichle, M. E., \& Gusnard, D. A. (2005). Intrinsic Brain Activity Sets the Stage for Expression of Motivated Behavior. The Journal of Comparative Neurology, 493, 167-176. http://dx.doi.org/10.1002/cne.20752

Raichle, M. E., MacLeod, A. M., Snyder, A. Z., Powers, W. J., Gusnard, D. A., \& Shulman, G. L. (2001). A Default Mode of Brain Function. Proceedings of the National Academy of Sciences of the United States of America, 98, 676-682. http://dx.doi.org/10.1073/pnas.98.2.676

Ramirez, S., Tonegawa, S., \& Liu, X. (2013). Identification and Optogenetic Manipulation of Memory Engrams in the Hippocampus. Frontiers in Behavioral Neuroscience, 7, 226.

Rorty, R. (1979). Philosophy and the Mirror of Nature. Princeton, NJ: Princeton University Press.

Sheehan, T. (1999). Martin Heidegger. In R. L. Arrington (Ed.), A Companion to the Philosophers. Oxford: Blackwell UK.

Sheehan, T. (2009). The Turn. In B. W. Davis (Ed.), Heidegger: Key Concepts (pp. 82-101). Durham: Acumen Publishing.

Sheehan, T. (2014). Making Sense of Heidegger: A Paradigm Shift (Kindle Edition, p. 112). Lanham, MD: Rowman \& Littlefield International.

Teresa of Avila (1577). Las moradas. Also Called "Castillo Interior”.

Thagard, P. (2014). Cognitive Science. In E. N. Zalta (Ed.), Stanford Encyclopedia of Philosophy (Fall 2014 Edition). Stanford, CA: Stanford University. 